\title{
A preliminary study of the effects of lime application on levels of facial eczema spores in pasture
}

\author{
P.J. GRIERSON \\ 587 Work Road, RD2, Katikati \\ jmgrierson@farmside.co.nz
}

\begin{abstract}
This research was completed for school science fairs, to see whether agricultural lime affects facial eczema spore numbers. Lime was applied at various rates on grazed plots, and using the Pithomyces chartarum (L) spore count wash method, the effect of lime on spore counts was measured. The residual effect of recent and past lime applications up to 3 years old was also measured. Lime applied at 2.5 tonnes/hectare killed nearly all of the spores within 5-8 days and maintained levels below the danger level of 50000 spores/g for several weeks (whilst spores were present). As well as this short term effect, 2007 spore counts on plots last treated with lime in 2006 and 2005 averaged 44167 and 35833 spores/g respectively which were well below the 2007 control plot counts, which averaged 123333 spores/g pasture. In these experiments, lime was effective at reducing facial eczema spore numbers when applied at $2.5 \mathrm{t} / \mathrm{ha}$, with up to 2 year's residual effect. Therefore tactical use of lime applications could potentially protect farmers and stock from the effects of facial eczema for up to 3 years.

Keywords: facial eczema, lime, Pithomyces chartarum (L), sporidesmin
\end{abstract}

\section{Introduction}

Facial eczema is caused by animals ingesting toxic spores from the saprophytic fungus Pithomyces chartarum (L) that grows in the dead litter layer of pasture. When climatic conditions are favourable, the fungus produces large numbers of these spores, which contain a toxin called sporidesmin. Sporidesmin causes severe and irreversible liver damage, and the liver damage is the underlying cause of the symptoms displayed in the animal (Te Ara 1966). Affected animals may suffer in two ways:

1. Liver damage - stock will be unwell, reduce feed intake, will stop gaining weight and may even lose weight. Dairy cows will show a drop in milk production, while sheep can show a reduction in wool production. Reproductive losses can be severe and deaths from sudden liver failure are common. Serious long-term health problems can occur in animals that have recovered from liver damage.

2. Photosensitivity - this is the most obvious sign of the disease and often only a few animals with liver damage show classic facial eczema symptoms. As a result of liver damage, the animal's skin can become overly sensitive to sunlight, a process called "photosensitization". This results in severe sunburn, mostly on the head and face and exposed areas of the body. Animals will be restless, seek shade and scratch or rub at their face and shake their head, their ears will tend to droop and the eyes may close as the face swells. Over the next few weeks, the burnt skin becomes thickened and leathery, and will eventually peel off.

\section{Treatment}

Affected animals are given special feeding, stress is kept to a minimum and they are given veterinary attention, while sunburnt animals should be given access to shade (Te Ara 1966). There is really no effective treatment for facial eczema once animals are affected by the toxin, so the emphasis should be on preventing the liver damage.

\section{Prevention}

There are several preventative measures that farmers can adopt. Resilience to facial eczema is genetic and animals can be selected and bred for resistance to the disease. Alternatively, pasture management is important to reduce both the build-up of toxic spores and spore intake.

Monitoring of temperature, rainfall and humidity and regular district spore counting and reporting is regular practice, to assist farmers to make prevention decisions.

Fungicide spraying of pasture is useful in some situations (Te Ara 1966) but the main method of prevention is by feeding high doses of zinc salts before and during the onset of high spore numbers, which neutralise the toxins in facial eczema (Te Ara 1966).

\section{Agricultural lime}

Lime is a soil amendment containing variable amounts of calcium carbonate (depending on source), which is actually just ground up limestone rock. Lime is relatively inexpensive compared to normal farm fertiliser products and is used to raise soil $\mathrm{pH}$. Where soil $\mathrm{pH}$ is increased from acid conditions (i.e., $\mathrm{pH} 5.0$ to 5.5) with lime application towards the optimum soil $\mathrm{pH}$ of 5.8 to 6.0 , pasture growth responses occur (Roberts \& Edmeades 1999) due to a number of mechanisms. Over time, some farmers have made the observation that facial eczema damage to stock does not occur to the same extent where paddocks have recently been treated with lime. There is 
some debate among farmers as to this and in 1981 research was carried out by MAF Agricultural Research Division in Hastings, which concluded that there was no significant difference between spore counts on limed and unlimed plots (Surveillance 1981). However, this trial was flawed as sampling was suspended just when spore counts were rising so the trial was not properly completed.

This project was undertaken because every year when there is a bad facial eczema outbreak thousands of farm animals in New Zealand get very sick or die. This can cost millions of dollars in production of meat, wool and milk, and many expensive and time-consuming prevention methods. This study was to test the farmer observation that lime assists in reducing the risks to livestock from facial eczema.

\section{Methods}

\section{Selection of plots and lime application}

Adjoining plots $20 \times 5 \mathrm{~m}$ were marked out on a Katikati deer farm pasture. The pasture was trimmed by mower to a medium height $(120 \mathrm{~mm})$ and lime (McDonalds Lime) was spread evenly over each plot at a rate of $2.5 \mathrm{t} /$ ha, leaving an untreated control plot. Lime treatments were repeated in 2005, 2006 and 2007 on new plots each year, with plots previously treated in 2005 and 2006 retained and not re-treated. These plots were used to measure residual effects. All plots including the control received normal fertiliser applications to maintain soil fertility levels.

\section{Sample collection}

Seven days after lime application (application dates: 10/ 04/05, 15/04/06, 04/03/07), spore counting commenced. Using scissors a pasture sample was harvested at about $2 \mathrm{~cm}$ height, ensuring each cut was about $1 \mathrm{~cm}$ wide and $3 \mathrm{~cm}$ long. The sample was placed in a plastic bag.

Further harvests in the same plot were collected by moving 3 metres diagonally to the right and then again 3 metres diagonally to the left. Harvesting was continued in this manner until at least $60 \mathrm{~g}$ of pasture was collected for each plot.

\section{Spore counting wash method}

The methodology used to count spores in this experiment was taken from Appendix III on the MAF website (www.maf.govt.nz).

Once separate pasture samples were collected from each plot, the contents of each bag was thoroughly mixed. A sample of $60 \mathrm{~g}$ pasture was weighed from each bag and added to $600 \mathrm{ml}$ of clean cold water in a glasspreserving jar. The mixture was then shaken vigorously for 3 minutes.

A small drop of the pasture/water mixture was collected on the end of a small clean pointed rod. This drop was placed gently on the edge of a haemocytometer slide, which had a cover slip over the grids. The water/ pasture mixture was carefully slid under the cover slip ensuring none of the mixture was on top of the cover slip. This procedure was repeated for the other grid on the other half of the slide.

Using a microscope with $100 \mathrm{x}$ magnification, the slide was placed underneath the microscope's lens and five counts of spores (in each corner and the centre section of the grid) were made and recorded, and this was repeated with the second grid on the slide.

The haemocytometer and cover slip were then cleaned thoroughly under clean water and dried carefully. The same water/pasture mixture was shaken again for 30 seconds, and the counting procedure repeated. This whole procedure was repeated for all treatment bags collected.

\section{Collating counts}

All spores counted from both counts above, for each separate treatment sample, were multiplied by 5000 to give a total spore count per gram of collected pasture.

Pasture sampling and spore counting continued weekly or fortnightly over a period of approximately 2 months.

\section{Results}

\section{Short term effects ( 2 months or less)}

In the short term, weekly or fortnightly sampling and spore counting showed that lime applied at $2.5 \mathrm{t} / \mathrm{ha}$ reduced the numbers of facial eczema spores within 5-8 days from 120000 to 30000 spores/g and maintained spore numbers below the danger level of 50000 spores/ g for several weeks (Table 1, Fig. 1). There was no within year replication of treatment plots which would allow statistical analysis to determine whether the difference in spore numbers was significant and solely an effect caused by lime application. However, the fact that the reductions were so large and were repeatable over 3 years strongly indicates that lime does reduce facial eczema spore numbers on pastures.

The range of percentage reduction in spore counts from the levels in the control (untreated with lime) plot, for the treated plots over the 3 years studied, was from $33 \%$ to $96 \%$, with a mean percentage reduction over all 3 years of $81 \%$. There were mean percentage reductions for 2005 of $76 \%, 2006$ of $83 \%$ and 2007 of $84 \%$ (Table $1)$.

\section{Long term residual effects}

As well as the short term effect seen above, 2007 spore counts on plots last treated with lime in 2006 (counts of 10000 to 50000 , mean of 35833 ) and 2005 (15000 to 
Table 1 Short term effects of lime application to pasture over 3 years on numbers of facial eczema spores.

\begin{tabular}{|c|c|c|c|c|c|}
\hline \multirow{2}{*}{ Year } & \multirow{2}{*}{ Test } & \multirow{2}{*}{ Date } & \multicolumn{2}{|c|}{ No. spores/g of leaf } & \multirow{2}{*}{$\%$ Reduction } \\
\hline & & & No lime & 2.5 t/ha lime & \\
\hline \multirow[t]{7}{*}{2005} & 1 & $17 / 04 / 2005$ & 100000 & 25000 & 75 \\
\hline & 2 & $18 / 04 / 2005$ & 60000 & 40000 & 33 \\
\hline & 3 & $19 / 04 / 2005$ & 70000 & 5000 & 93 \\
\hline & 4 & 20/04/2005 & 75000 & 15000 & 80 \\
\hline & 5 & 21/04/2005 & 40000 & 10000 & 75 \\
\hline & 6 & 22/04/2005 & 70000 & 5000 & 93 \\
\hline & 7 & 23/04/2005 & 30000 & 5000 & 83 \\
\hline Average 2005 & & & & & 76 \\
\hline \multirow[t]{7}{*}{2006} & 1 & $22 / 04 / 2006$ & 45000 & 15000 & 67 \\
\hline & 2 & $24 / 04 / 2006$ & 85000 & 20000 & 77 \\
\hline & 3 & $26 / 04 / 2006$ & 140000 & 5000 & 96 \\
\hline & 4 & 1/05/2006 & 85000 & 5000 & 94 \\
\hline & 5 & $4 / 05 / 2006$ & 110000 & 25000 & 77 \\
\hline & 6 & $5 / 05 / 2006$ & 95000 & 20000 & 79 \\
\hline & 7 & $7 / 05 / 2006$ & 50000 & 5000 & 90 \\
\hline Average 2006 & & & & & 83 \\
\hline \multirow[t]{6}{*}{2007} & 1 & $11 / 03 / 2007$ & 120000 & 30000 & 75 \\
\hline & 2 & $25 / 03 / 2007$ & 95000 & 15000 & 84 \\
\hline & 3 & $7 / 04 / 2007$ & 100000 & 10000 & 90 \\
\hline & 4 & $14 / 04 / 2007$ & 185000 & 30000 & 84 \\
\hline & 5 & $28 / 04 / 2007$ & 170000 & 30000 & 82 \\
\hline & 6 & $5 / 05 / 2007$ & 70000 & 10000 & 86 \\
\hline Average 2007 & & & & & 84 \\
\hline Average $2005-2007$ & & & & & 81 \\
\hline
\end{tabular}

60000 , mean of 44 167) were on average considerably below the 2007 control plot which had counts ranging from 70000 to 185000 , with a mean of 123333 (Fig. 2, Tables 2).

\section{Discussion}

Lime appears to be effective at controlling facial eczema spore numbers when applied at $2.5 \mathrm{t} / \mathrm{ha}$, both over a short time of 2 months and with up to 2 years residual effect. Thus, lime application at $2.5 \mathrm{t} / \mathrm{ha}$ incorporated into a normal fertiliser programme could protect farmers and stock from the effects of facial eczema for up to 3 years.

Lime appeared to deform the spores when observed through the microscope and possibly killed them, which slowed the build up of potentially dangerous levels of facial eczema. The most likely cause for this is that the alkalinity of the lime affected the fungus, which produced the spores or the spores themselves. Changes in soil and litter $\mathrm{pH}$ cause disruption to cellular surfaces of germinating fungi which affects fungus function (Anonymous 2006). Lime has a range of particle sizes with a percentage of very fine particles, and so it manages to cover the whole of the pasture, not just part, therefore getting down to the base of the pasture where the fungus likes to live.
In a rate of lime experiment conducted in the 2006 season, $1 \mathrm{t} / \mathrm{ha}$ was less effective at reducing spore numbers than $2.5 \mathrm{t} /$ ha and $0.5 \mathrm{t} /$ ha lime was too little to have a large effect (Grierson 2006). However, all lime rates reduced the spore counts on the treated plots proportional to the amount of lime applied. Based on the results of this study it is recommended that farmers apply $2.5 \mathrm{t}$ lime/ha.

One problem encountered in an experiment such as this, was that the facial eczema spores generally only appear for 3 months of the year, and sometimes not at all if the weather conditions are not right. In order to ensure that sufficient spores were present prior to the commencement of the experiment, an early spore count assessment was conducted when weather conditions were still quite humid. Another problem encountered was torrential rain at times during the experiment, which can wash all of the spores off the pasture. When this occurred, spore counting was ceased temporarily giving the spores time to recover after the rain, then testing was restarted. This worked very well and the spores recovered almost to pre-rain levels.

Possible further investigations could be to study:

- how long the effect of lime lasts beyond 2 years

- what is the actual mechanism that is reducing spore numbers 
Figure 1 Effect of lime (2.5 t/ha) on facial eczema spore numbers, 2005 to 2007 seasons. For sample dates see Table 1.

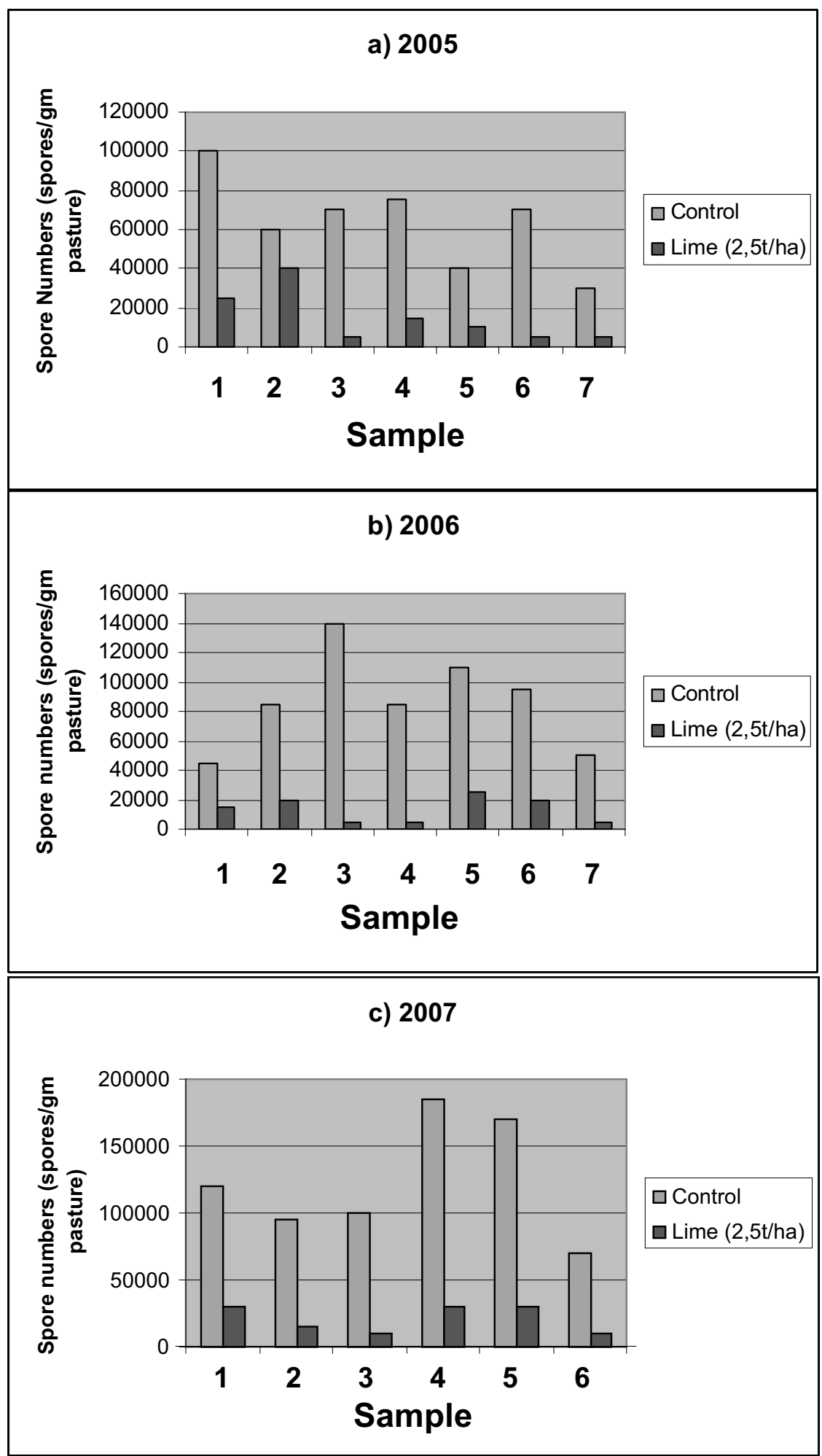


Figure 2 Residual effects of lime application at $2.5 \mathrm{~kg} / \mathrm{ha}$ in 2005 and 2006 on facial eczema spore counts in 2007.

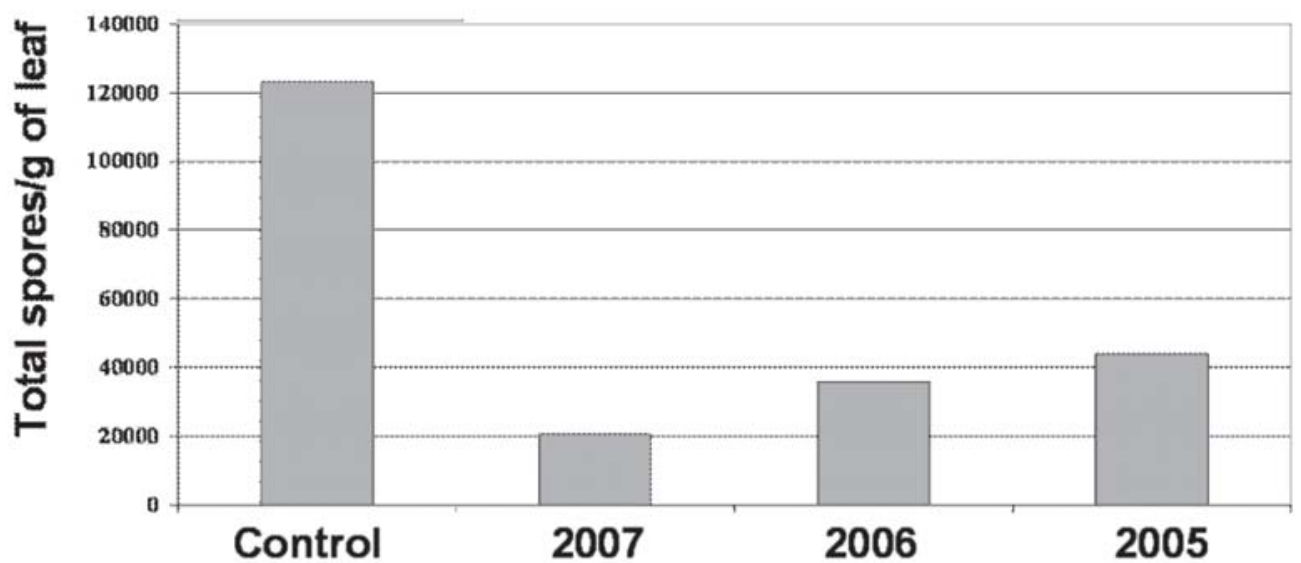

\section{Lime treatment}

Table 2 Long term residual effects of lime application (2.5 t/ha) to pasture over 3 years on numbers of facial eczema spores compared with a control without lime.

\begin{tabular}{|c|c|c|c|}
\hline Test & Treatment & Sample date & $\begin{array}{c}\text { Total spores per } \\
\mathrm{g} \text { of leaf }\end{array}$ \\
\hline 1 & 2005 Lime & $11 / 03 / 2007$ & 60000 \\
\hline 1 & 2006 Lime & $11 / 03 / 2007$ & 50000 \\
\hline 1 & 2007 Lime & $11 / 03 / 2007$ & 30000 \\
\hline 1 & Control & $11 / 03 / 2007$ & 120000 \\
\hline 2 & 2005 Lime & $25 / 03 / 2007$ & 30000 \\
\hline 2 & 2006 Lime & $25 / 03 / 2007$ & 40000 \\
\hline 2 & 2007 Lime & $25 / 03 / 2007$ & 15000 \\
\hline 2 & Control & $25 / 03 / 2007$ & 95000 \\
\hline 3 & 2005 Lime & $7 / 04 / 2007$ & 60000 \\
\hline 3 & 2006 Lime & $7 / 04 / 2007$ & 30000 \\
\hline 3 & 2007 Lime & $7 / 04 / 2007$ & 10000 \\
\hline 3 & Control & $7 / 04 / 2007$ & 100000 \\
\hline 4 & 2005 Lime & $14 / 04 / 2007$ & 50000 \\
\hline 4 & 2006 Lime & $14 / 04 / 2007$ & 45000 \\
\hline 4 & 2007 Lime & $14 / 04 / 2007$ & 30000 \\
\hline 4 & Control & $14 / 04 / 2007$ & 185000 \\
\hline 5 & 2005 Lime & $28 / 04 / 2007$ & 50000 \\
\hline 5 & 2006 Lime & $28 / 04 / 2007$ & 40000 \\
\hline 5 & 2007 Lime & $28 / 04 / 2007$ & 30000 \\
\hline 5 & Control & $28 / 04 / 2007$ & 170000 \\
\hline 6 & 2007 Lime & $5 / 05 / 2007$ & 10000 \\
\hline 6 & 2005 Lime & $5 / 05 / 2007$ & 15000 \\
\hline 6 & 2006 Lime & $5 / 05 / 2007$ & 10000 \\
\hline 6 & Control & $5 / 05 / 2007$ & 70000 \\
\hline \multirow[t]{4}{*}{ Average } & 2005 Lime & & 44167 \\
\hline & 2006 Lime & & 35833 \\
\hline & 2007 Lime & & 20833 \\
\hline & Control & & 123333 \\
\hline
\end{tabular}


- the effects of other types of lime

- whether lime works the same way in other geographic areas

- whether other alkaline materials such as RPR have a similar effect.

\section{ACKNOWLEDGEMENTS}

I would like to acknowledge and thank my parents John and Michelle Grierson, Ross Duder, Chris Morris and Ants Roberts, all of who helped in the work or discussions around the results of the work.

\section{REFERENCES}

Anonymous. 2006. Nova Chemical Manual 2006/07. p. 207. In: Organic Crop Protection Pty., Australia.

Grierson, P.J. 2006. Fighting facial eczema. Exhibit, Bay of Plenty Regional Science and Technology Fair 2006. MAF website. Appendix III. The "wash" method for facial eczema spore counting on pasture. http:// www.maf.govt.nz/sff/about-projects/search/L01-018/ appendises.pdf

Roberts, A.H.C; Edmeades, D.C. 1999. Fertilizer Use on New Zealand Dairy Farms. 2nd Revised Edition. New Zealand Fertilizer Manufacturer's Association, Auckland, N.Z. 36p.

Surveillance. 1981. Vol. 8(3). MAF, Wellington, New Zealand.

Te Ara 1966. Encyclopaedia of New Zealand. FACIAL ECZEMA - Sheep and Cattle Disease. http:// www.teara.govt.nz/1966/F/FacialEczema/ SheepAndCattleDisease/en - 1966 Encyclopaedia of New Zealand -

Te Ara 1966. Encyclopaedia of New Zealand. FACIAL ECZEMA- Methods of Prevention. http:// www.teara.govt.nz/1966/F/FacialEczema/ MethodsOfPrevention/en 